\title{
Combined Fractures in the Capitellum and the Radial Head Associated with Medial Capsular Avulsion
}

\author{
TAKASHI SOEJIMA, NORIYUKI ANDO, HYOUTA ISHIDA, KENJI YOSHIDA \\ AND KENSEI NAGATA
}

Department of Orthopaedic Surgery, Kurume University School of Medicine, Kurume 830-0011, Japan

\begin{abstract}
Summary: We present a case with an unusual fracture. A 28-year-old man presented a painful and swollen left elbow after falling down. Radiographs revealed combined fractures in the capitellum and the radial head associated with a medial capsular avulsion. Two osteochondral fragments from the capitellum were found at the operation. One was the free fragment revealed on radiographic examination. Another was not revealed before the operation and was found piercing the fracture line of the radial head. These two fragments were removed. The radial head fracture was reduced and was fixed using two Herbert screws. It is very difficult to detect a fragment of the capitellum that impaled the radial head on a plain radiogram before operation. Also, a capsular injury and/or ligamentous injury is often overlooked. This fact should be kept in mind whenever a non-operatively treated radial head fracture fails to respond as expected.
\end{abstract}

Key words capitellum, radial head, fracture

\section{INTRODUCTION}

A fracture in the radial head accounts for about $10 \%$ of all forearm fractures [8]. However, a fracture in the radial head together with a fracture in the capitellum of the humerus is rare. The co-incidence was only $1.7 \%$ in one series of a radial head fracture [4]. In the literature, there is only brief mentions in larger series of an isolated radial or capitellum fractures with little detail, and case reports have been very few.

Here, we present a rare case with interesting findings of a fracture in the radial head co-incidence with a fracture in the capitellum.

\section{CASE REPORT}

A 28-year-old man presented a painful and swollen left elbow after falling down. Radiographs revealed a fracture in the radial head associated with a shell-like fragment from the capitellum (Fig. 1A).
The radial head fracture was classified as type I according to Mason's classification while the capitellum fracture was graded as Grade I according to Grantham's grading system [9]. In addition, a chip fragment was detected near the medial capsular attachment of the humerus (Fig. 1B).

The patient underwent surgery at 10 days after the trauma. The humeroradial joint was exposed through the posterolateral approach. The radial head was found to be fractured into three parts (Fig. 2A). Two osteochondral fragments from the capitellum were found together with the radial head fracture (Fig. 2B). One was the free fragment revealed on radiographic examination. Another was not revealed before the operation and was found piercing the fracture line of the radial head. These two fragments were removed. The radial head fracture was reduced and was fixed using two Herbert screws. After using a posterior slab with the elbow flexed to $90^{\circ}$ for 3 weeks, the patient underwent physiotherapy.

At 13 months later, the radial head fracture showed full bony union and the patient had no pain. 


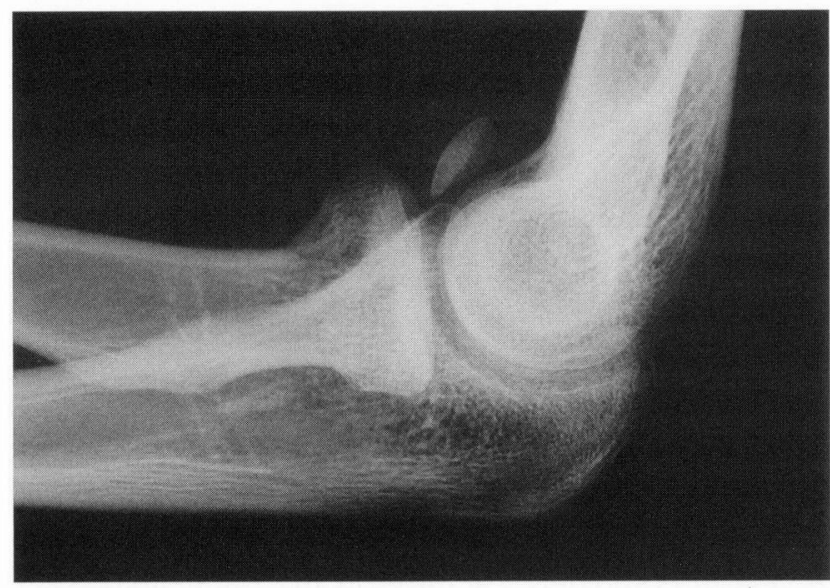

A

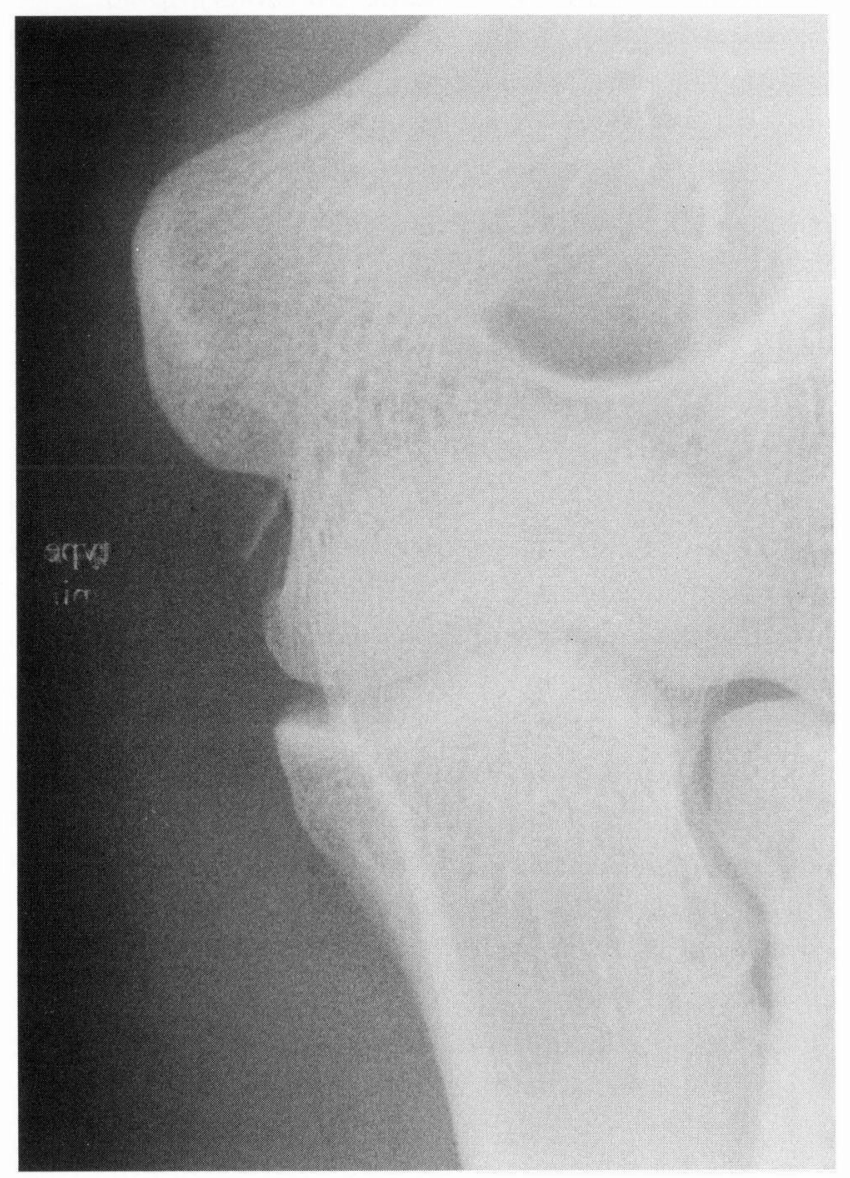

B

Fig. 1A. The lateral radiogram on admission.

$1 B$. The anteroposterior radiogram of the humeroulnar joint.

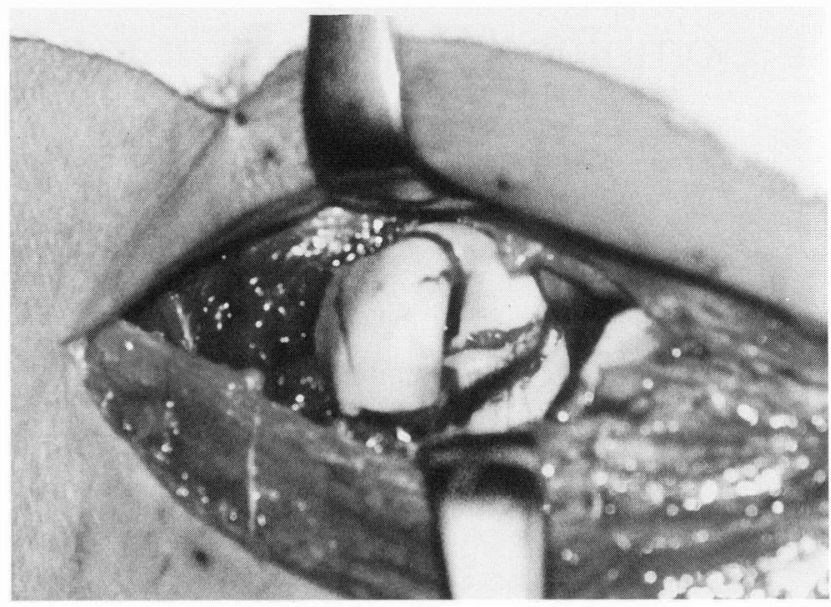

A

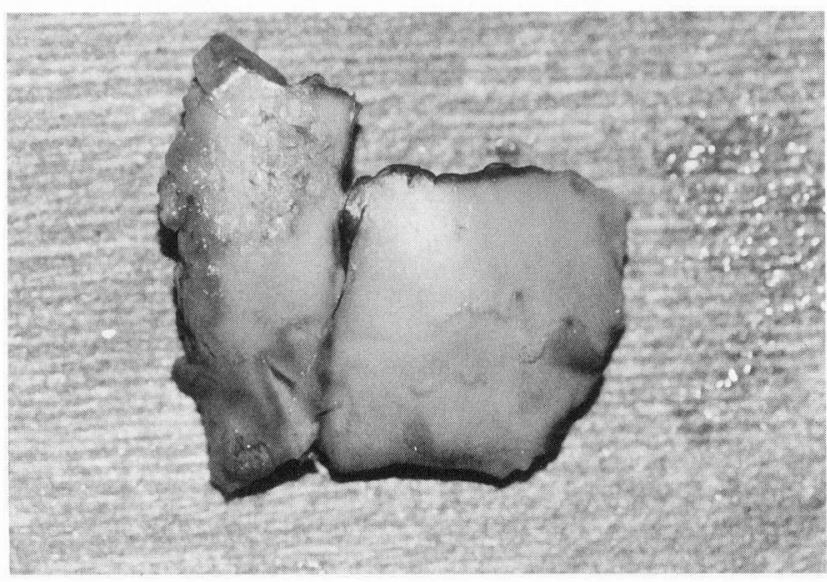

B

Fig. 2A. Intraoperative view of the radial head

$2 B$. Two osteochondral fragments from the capitellum. Left side; A fragment impaling into the fracture line, running anteroposteriorly, of the radial head. Right side; A free fragment in the elbow joint.

However, the full-range of motion of the elbow was not recovered; the extension range was $-35^{\circ}$, flexion was $120^{\circ}$, supination was $40^{\circ}$, and pronation was $75^{\circ}$.

\section{DISCUSSION}

Milch was the first to describe cases of combined fractures in the capitellum and radial head [5]. Since then, there has been a few isolated case reports $[2,5,6,8,9]$, or brief mentions in larger series of a radial head fracture or in larger series of a capitellum fracture $[1,3,4,7]$.

The finding of a fragment of the capitellum that impaled the radial head has been reported 3 times to 
date $[5,6,9]$. The finding of a combined medial collateral ligament injury or a medial capsular injury has been reported only twice [2,9]. These findings occurred in cases when the fractures in the capitellum and the radial head were not serious. This may be due to the difficulty in detecting a fragment of the capitellum that impaled the radial head on a plain radiogram before operation. Also, a capsular injury and/or ligamentous injury is often overlooked. Accordingly, the real incidence rate of these findings in this combined fracture may be greater than so far reported. In the future, MRI evaluation and/or arthroscopic examination will be needed, even if the radial head fracture or the capitellum fracture is treated conservatively.

\section{REFERENCES}

1. Collert S. Surgical management of fracture of the capitellum humeri. Acta Orthop Scand 1977; 48:603-606.

2. Hendel D, and Halperin N. Fracture of the radial head and capitellum humeri with rupture of the medial collateral ligament of the elbow. Injury 1982; 14:98-99.

3. Lansinger $\mathrm{O}$, and Mare $\mathrm{K}$. Fracture of the capitellum humeri. Acta Orthop Scand 1981; 52:39-44.

4. MacDonald JA, and McGoey PF. Fracture of the articular portion of the capitellum of the humerus in adults. Can Med Assoc J 1959; 81:634-636.

5. Milch $H$. Unusual fractures of the capitellum humeri and the capitellum radii. J Bone Joint Surg Am 1931; 13:882886.

6. Newman JH. Letter to the editor. Injury 1982; 14:477.

7. Palmer I. The validity of the rule of alternativity in traumatology. Acta Chir Scand 1961; 121:481.

8. Reith PL. Fracture of the radial head: associated with chip fracture of the capitellum in adults-surgical considerations. South Surg 1948; 14:154-159.

9. Ward WG, and Nunley JA. Concomitant fractures of the capitellum and radial head. J Orthop Trauma 1988; 2:110-116. 